centrally, leaving a large cup-like cavity surrounded by large nnequal fungations. The mamma was larger and harder. Owing to objections from the patient no hypodermic injection had been given since Dec. 14th. On the 23rd three minims were injected but no reaction followed. On Jan. 11 th, 1896 , the tumour centrally had sloughed almost flush with the thorax. There was marginal increase. Four minims of fresh Coley's fluid were injected into the marginal fungations, which produced a vigorous reaction in half an hour, with rigors and romiting, followed by stupor and difficult locomotion, and succeeded by a deep sleep lasting all night. From this date to March 19 th the injections were fairly regular at intervals of a few days. There was free serous discharge from the tumour, especially from the central cavity. The marginal growths were thinning perceptibly. Rigors, and often retching or vomiting, nearly always followed the injections. The patient was daily lo:ing weight and strength, and the growth was slowly but steadily increasing in size, it then measuring four inches by three inches. An eczematous, patchy condition of the skin appeared on the forehead, eyelids, and extensor surfaces of the knees and elbows, with exfoliation. The skin of the fingers and palms cracked and peeled. At this stage, as no appreciable benefit had been derived, the injections were stayed.

On Dac. 7th, 1896, the tumour was found to extend from the angle of the right scapula to the axillary half of the right mamma, and above from the apex of the axilla to a line drawn from the lower border of the marnma to the inferior angle of the scapula. The pectorales muscles were pushed forward by the growth; the right arm was twice its normal size from codema, and the clavicular glands were markedly increased in size and hardness. The mamma itself was badly infiltrated and partly sloughing. Mitigation of the agonising pain and sleeplessness experienced by the patient was derived from morphia pills, of which she daily took up to two grains. The local treatment throughout was an endeavour to keep the fungating masses dry, sweet, and clean by various powders and antiseptic washes.

On Des, 23rd the patient became semi-comatose and, without regainiog consciousness, died on Dec. 27th, 1896. The usual Jewish objections to post-mortem examination prevented me following the case further; but external abdominal examination showed that there was immense hepatic enlargement, the lower margin almost reaching the iliac crest.

Remarks. - The value of Coley's fluid, as gathered from the foregoing notes, has been, in this case of carcinoma, I fear, practically nil. True, in the early stage of the disease I fancied the rate of growth was checked and the fœetor of the discharge lessened, but the terribly alarming reactions after injection, and the final skin effects, as noted, induced me to desist from a further course of treatment.

Bow, E.

\section{SOME REMARKS ON PLAGUE.}

\section{By J. A. LOWSON, M.B., C.M. EdIN.}

A FEW remarks on some plague questions may not be out of place at a time when Europe is threatened with invasion by an old enemy, and especially as a late paper on the subject-viz., that by Dr. Cantlie before the Epidemiological Society on Dec. 18th, 1896-contains inaccuracies regarding the Hong-Kong epidemic as well as opinions which are not shared by several of those whose experience of the disease bas been very much greater than his. Full treatment of these sabjects can scarcely be gone into, as considerations of time and space do not permit at present.

\section{Nomenclature.}

Any change in the nomenclature of the disease is greatly to be deprecated; there is really no necessity for it. In Hong-Kong those of us who were constantly cescribing the disease to medical visitors had occasion to call it a malignant polyadenitis some time before Dr. Cantlie ever saw a case. It will be time to change the name when we find that plague includes two or more diseases, as typhus fever did in days gone by. At present, however, there seems to be little danger of the name "malignant polyadenitis" taking root; one might as well apply it to syphilis as to plague.

\section{Distribution}

The present known limits of plague have not been correctly laid down by Dr. Cantlie. I have very little doubt myself that plague has made its way over Europe, Asia, and Africa in past days. In the course of desultory reading I came to the corclusion that the East Coast of Africia at least had suffered from the disease futher south than a limit of nineteen degrees north, but without medical authority at hand refrained from mertioning this at the Epidemiological Society's meeting when plague was discussed. Since that time I find that plague is well known in Equatorial Africa, and through the courtesy of Mr. Peter Rattray of Dundee, lately in Uganda, some interesting details can be given. The disease in the Uganda district is known as "kaumpuli" and is well known there. In a dictionary edited by Pilkington and printed by the Church Blissionary Society in 1892 the definition of this word is given thus :"The plague-a disease attended generally by a swelling of the glands, pain in the chest, very prevalent after the rains. Treatment: Blisters on the swollen parts and an emetic is the most successful." I understand Captain Ashburnbam of the Rifle Brigade nursed a European through the disease out there. I hope to get further information on the African distribution of the disease. When a native is attacked the whole tribe remove to another district at oncesound policy easily carried out because of its inexpensive character. Uganda is practically on the Equator, and although almost 4000 feet above the level of the sea the mean temperature should be nearer $90^{\circ}$ than $80^{\circ} \mathrm{F}$. The usual afternoon temperature in the shade is about $98^{\circ}$ in the dry season, slightly less in the rainy season. This surely does away with Dr. Cantlie's limits and the ingenious suggestion of Dr. Payne that the isothermal line of $78^{\circ}$ may stop the march of the disease. If the disease is well known in the centre of Africa it must bave found its way there; and I will not be surprised, now that attention has been directed to the subject, to hear that it is met with in other tracts of Africa. It seems peculiar that Stanley and other explorers have nothing to say on the subject, the information I had previous to Mr. Rattray's being founded on missionary lay reports on the disease.

In Singapore in the latter end of 1895 or early in 1896 the death-rate was abnormally high (from sixty to seventy-five per mille per annum) for several weeks, and some malignant disease was presumably " hanging around." The authorities there, however, reported that no plague cxisted. In 1896 three cases of plague were landed in Hong. Kong from ships arriving from Singapore, and although two cases could be explained away by long periods of incubation or other loophole, one case-that of an Indian servant on a Calcutta liner-leads me to conclude that he must have been infected in Singapore. He was perfectly well when he left Calcutta and no swellings of any kind whatever were present prior to his arrival at Singapore, yet after being on shore in Singapore he became severely ill in three days, ty pical plague glands formed, and he was landed at Hong-Kong to die Even the medical officer of health who saw the gland and had had previous plague experience did not think it was plague at first, but it was an undoubted and typical case. From the inquiries made of the man I could not trace any other source of infection, such as by fomites, \&o, on the ship. Calcutta at that time was not infected, so, if my conclusion be right, Singapore is another equatorial spot to be added to the geography of plague colonies. I trust further explanation will be forthcoming. So far, if it has been in Singapore it has not done much damage.

The evidence regarding Uganda, however, must convince us that plague will march and flourish wherever it is carried and finds a suitable pabulum-irrespectively of the ordinary temperatures we find on this earth.

\section{Pestis Minor and Pestis Ambulans.}

It is to be hoped these two terms will be kept distinct when further discussion occurs. Pestis minor is that bubonic disease which occurs (?) before an outbreak of plague, whilst pestis ambulans is the designation applied to glandular enlargements occurring during or af $t \in \mathrm{r}$ an epidemic which may probably be due to a less potent infecting power.

Ptstis minor.-The Hong. Kong experience in this respect 
requires notice. Dr. Cantlie said in his paper that all his ideas on the subject had been changed in a $\mathrm{few}$ days owing to the reputed discovery in the blood of patients suffering from buboes in Calcutta of a bacillus similar to the plague bacillus. Since 1889 Dr. Atkinson has placed the venereal wards especially of the Government Civil Hospital in my hands, and the records of excision and scraping of glands in that institution given by Dr. Cantlie cannot enter a plague report at all. Before the Hong-Kong and China Branch of the British Medical Association I read a paper in 1893 entitled, "On Venereal Disease in the Far East and the Repeal of the Contagious Diseases Act," and stated that all these cases of inguinal bubo which I had operated on were venereal in origin, in most cases due to a preceding chancre, in some cases due to gonorrhcea; in every case an antecedent venereal history was obtained. I think it must have been at this same meeting that Dr. Cantlie gave the definition of the bubo published in THE LANCET of Jan. 2nd, 1897. The majority of the members at that time gave a similar experience to that obtained at the Government Civil Hospital, and if further inquiries had been carried out perhaps Dr. Cantlie might have modified his statements on these cases, many of which probably were of that kind of patient who did not want to have venereal disease as a cause of absence from work. It was surely remariable that they all occurred in the inguinal glands, more remarkable still that they all occured in men. No comparison could be drawn between the years I have mentioned and those previous, as radical treatment such as excision at least was seldom, if ever, attempted. I have been informed by some of the older practitioners of the East that the same type of bubo has been in evidence for as long as they can remember in China. I have seen very few of the non-venereal buboes mentioned by Dr. Manson, and in all there was some cause for the enlargement such as continued irritation from morphia injection, old injury, elephantiasis, or other similar mischief. In one case excessive copulation seemed to be the cause of an inguinal bubo, but after a few days on Easton's Syrup a slight discharge from the penis took place, which proved to be the remains of an old gonorrhcea. A peculiar form of $1 y$ mphangitis appeared in the garrison of Port Hamilton in 1886-87 and was reported by Surgeon $\mathbf{A}$. J. Wildey, R N., in the Transactions of the Hong-Kong Medical Society pablished in 1889. Here there was a lymphatic disease of a somewhat epidemic character, but it cannot be said it was the forerunner of plague or in any way associated with it.

The children's epidemic glandular disease related by Dr. Cantlie in 1891 was certainly peculiar, but he forgets to mention that at the time he was fully convinced it was mumps. I saw several cases of true mumps about that time, but knew nothing of Dr. Cantlie's cases until he read his paper before the British Medical Association, Hong-Kong branch. It was singular that no adults were affected, and although a close watch was kept in the Government Civil Hospital afterwards no cases were ever seen by the medical officers there. Godding's cases coming after the plague, if related to that disease at all, should be treated under the heading of pestis ambulans. They were very like those narrated by Surgeon A. J. Wildey, R.N., and the danger of plague on board men-of-war may be the next scare for the Admiralty.

I contend that the Hong-Kong cases mentioned above have no relation to plague and cannot be classed as pestis minor-that bubonic plague in its severe type was introduced straight into Hong-Kong without any mongrel form intervening. In 1893, when these bubjes were discussed, I mensioned that, not to be behind Dr. Cantlie, I hoped to discover the bacillus bubonicus Lowsonii, but have to confess to having failed up to the present moment. I have asked several medical men in America to keep watch on their bubo cases, many of which show the same characteristics which have been noted in the East-their results may be expected presently. The Calcutta cases should be "thrashed out" by the medical men there. The reports already received give good grounds for scepticism.

The reports of the Russian outbreak in 1877-79 leave no doubt that Dr. Döppner saw some cases which at present have the best claim to be classed as pestis minor ; but what a different description to those of the Far East. "They had abscesses of the lymphatic glands either of the groin or the armpit which were suppurating freely:" Again: "It was marked by a period of feverishness occasionally extending to a fortuight, but usually of a shorter duration, followed by the development of buboes in the submaxillary, axillary, and rural regions, but most frequently in the submaxillary region." If my memory is correct none of Dr. Cantlie's children's cases suppurated; they resolved, as the usual parotiditis caused by mumps in this country does. In most hospitals in Britain a certain number of lymphatic abscesses occur every year, and it has been the same in Hong-Kong. Mr. Rattray informs me that in Uganda many natives came to him with swollen glands and said they had " kaumpuli," but that in every case he found some ordinary cause for the condition.

I trust these remarks will remove any false impression Dr. Cantlie's remarks may have given regarding the subject of pestis minor in Hong-Kong in 1894.

Pestis ambulans.-After the 1884 outbreak it was only natural that some glandular cases should occur where there was doubt in diagnosis, and in several such I examined microscopically the blood and gland "juice" without finding a trace of the plague bacillus. I made no culture experiments. In most acute infectious diseases a minor infecting power has been proved-cholera, influenza, and diphtheria being common examples; but in plague so far I have not met it, unless a slightly greater percentage of recoveries towards the end of an epidemic is attributable to this cause. A very careful history has to be got before ambulatory plague can sometimes be excluded, and so far I do not know if the plague bacillus has ever been found in pestis ambulans. It seems possible that a small amount of the toxin may be somehow absorbed by the body to cause slight glandular enlargement without the necessary entrance of bacilli, as the products of the bacilli may hang about a neighbourhood long after all bacilli are dead. One case sent in by Dr. Cantlie will illustrate the difficulty of diagnosis sometimes met with. A Parsee was admitted with slight elevation of temperature and enlargement of glands in the left femoral region. Preliminary examination of blood was negative and no cause could be found for the enlargement until a nocturnal specimen of blood showed we were dealing with a case of filaria sanguinis hominis. This was a purely accidental occurrence-the examination of a 9 P.M. specimen of blood; but for this we might have had this case puzzling us still for a diagnosis. The only case during the epidemic - or rather immediately afterwards-which was really doubtful was that of one of our nurses whom I was requested to see after she bad been ailing for some time with lymphatic inflammation of the right leg and femoral lymphadenitis. Four or five weeks previously she had had some pain in the groin simultaneously with pain extending down the lymphatics of the leg to the knee, and it was only when the lymphangitis was well marked down almost to the toes that she complained and took to bed. For several reasons it was deemed unwise to make a puncture in the gland, so no microscopical examina. tion was made. Recurrent attacks of lymphangitis followed, with occasional enlargement of the gland, such as is seen sometimes in any large hospital, and the conclusion was come to that it was not due to plague infection. This is the only case seen which has been left in doubt. During 1895 cases of ambulatory plague were still looked for carefully, but none turned up which could be classed under that heading-in fact, the so-called sporadic cases showed no lessening of virulence, with the result that every case died if my memory serves me right. In Swatow several cases occurred, so I am informed, but of these more evidence is required yet. While on this subject it is right to mention that many mistakes have been made by competent men when examining blood or bubonic tissue for the plague bacilli, and it requires some time for even a man who has done some laboratory work to be sure of the correctness of his examination.

(4) Infection. (a) Method of Leaving the Body; (b) Mode of Infection; and (c) Carriage and Spread of Infection.

(a) Method of leaving the body.-One certain but in frequent channel is by the discharge from buboes. The bacilli are numerous in such discharge, and even after it becomes purulent some days elapse as a rule before the bacilli disappear and the infecting power is lost. This loss of infecting power will explain why the experiments which have heretofore been made by inoculating man and animals have failed, and the statement has consequently been made that the discharge from buboes was not infective. After some days' suppuration the pus has no more infecting power than that from a simple ulcer. The reason why this channel of exit is infrequent is that death generally supervenes before any vent to the discharge is made or required. Out of aboul 
2300 cases seen in the Hong-Kong Chinese hospitals certainly not fifty buboes suppurated and burst, whilst in Macao and Canton I only noticed other two such cases amongst large numbers of plague-affected patients. The freces are infective. The most complete experiments on this subject were made by Staff-Surgeon Wilm, who was working with us in Hong-Kong. ${ }^{1}$ In every case he experimented on culture from a plague patient's fæces gave positive results as to the presence of the plague germ. In cases where albuminuria and casts were found bacilli were also present in the urine. The sputum almost always contains them, as also the fur on the tongue. At present there is no evidence to show that the milk is infective. I doubt it, as many children who were suckled by their plague-stricken mothers were left on our hands in hospital. Still, it is possible that such children were able to resist infection by the alimentary tract or mouth inoculation. No bacteriological experiments were made. The bacilli have so far not been found in the sweat secretion and I do not think in pure sweat they will be obtained. All culture experiments so far have failed. I believe there is little or no danger of infection by the breath of a plague patient. In Hong-Kong, had this danger been great, certainly more deaths would have occurred amongst those occupied in plague work. In the house-to-house visitation party who went round twice daily and entered the most infective houses in the city no one took the disease. Their duties only necessitated examination of the inmates of a house and their removal when suffering from plague, with a minimum of interference as far as movement of furniture or dirt was concerned. At the height of the epidemic these men spent the best part of two hours twice daily in the worst infected houses in the city. I certainly do not agree with the view that prolonged exposure to, and respiration of, "plague atmosphere" is necessary to get plague. A lengthened exposure only adds to the possibilities of a man getting it; he might get it from merely looking in at the door and getting a whiff of dust from the floor blown into his face; it is plague dust and dirt which are the infecting agents in houses. The cleansing squad of soldiers suffered, however-those who had to remove the dirt after stirring it up-and these only suffered when a preliminary disinfection was not carried out. After primary disinfection had been thoroughly set going none of these soldiers took plague. Several of the sanitary board's men who drove the dirt and refuse and shovelled it on to the fires on the Praga died, but, in contrast to this, notice how the attendants in hospitals fared. During the first ten days of the epidemic the hospital ship Hygeia was overcrowded (considering the hot, still atmosphere in the harbour), and the lower deck especially threatened to be dangerous, the smell of patients lying in dirty clothing being sickening and causing frequent emesis amongst those looking after their welfare, reduced in numbers and unable to get through all their bathing duties on account of many of the "boys" having fled. In this "hole" not one of these remaining attendants took the disease, although they were frequently fourteen hours on duty there. A Chinese hospital (the old glass works) was opened shortly after, and in forty-eight hours the building was crowded with dead and dying and the condition of affairs under Chinese management grew most alarming. Here were wards full of patients looked after by Chinese attendants, who religiously kept all windows and doors closed whenever a European's back was turned, and who often slept in the same rooms as their patients, only separated from them by a partition extending half way up to the ceiling, Not one of these got plague, although they were breathing as thick a "plague atmosphere" as one could desire. Even some days after, when free disinfection of the floors took place every morning when being swept, the atmosphere during the night was indescribably bad. The deaths of hospital attendants in 1894 were only two in number in Hong.Kong. The first to contract the disease was a Eurasian Roman Catholic sister at work in the Alice Jemorial Matshed Hospital, the cleanliness of which was undoubted; but the sister having had no previous experi ence of nursing it is probable that some indiscretion was the cause of infection. Incidentally I would remark that the most stringent instructions to be careful should be giren to all attendants and any carelessness punished at once-even by dismissal if other attendants can be had. The other case was that of an Amah in the Chinese hospital (the new abattoirs), where hygiene was

\footnotetext{
1 See Report to the Hong-Kong Government on the subject, 1896.
}

perfect so far as the building was concerned. Here, again, there was ignorance of nursing, not to mention the fact that the woman had to do the washing of patients' bedclothes, $\& c$, in addition. At a Chinese hospital outside Hong Kong one attendant took the plague and oied. This hospital was meagrely supplied with lime as a disinfectant. At a large hospital I visited in Canton after the plague bad been raging there for three months none of the attendants so far had taken the disease although they lived practically with the patients-some of the attendants' friends actually sleeping in the same small room. In this case, however, actual contact with the patient was rare, as the latter were allowed to die in their old clothes and were only occasionally supplied with tea or medicine (?) out of a pot or Chinese buwl. This hospital used no disinfectants. The walls of the small rooms had been whitewashed before the epidemic began ard the floors were simply swept up after each patient died and a new mat was placed upon the bed board, the old one being generally destroyed. I contend that in the case of the lower deck of the Hygeia (for some days, at least), in the Glassworks Hospital and the Canton Hospital the con. dition of the atmosphere as far as bcing laden with the expired air of plague patients could not have been worse ; the attendants had every opportunity, from length of time employed, of inhaling it for hours on end, yet rone took it, and one is forced to believe that the mere expired air of a plague patient cannot have much, if any, potrncy. The infection of plague in this respect I liken to phthisis, the sputrum here again conveying the infeoling matter. Further, the majority of houses in Hong-Kong consist of a ground-floor and first-floor, in many cases a second-flor $r$, and occasionally a basement. These floors are connected by a wooden stair inside the house shut off from the dwelling parts by a badly put together wooden partition, in some cases not reaching up to the ceiling. Now the atmosphere of this house is practically the same all through, yet often the inhabitants of single floors would be swept away and the others escape scot free. These floors were attacked indiscriminately - the first-floor or secord floor seeming to be attacked with greater regularity than the ground-flocr, probably because the last was more exposed to the fresh air and sunlight and had a larger exit for refuse. This impartiality in attack of floors is also a strong point against those who pin so much faith to the theory that the soil originates or harbours the disease and that the order of attack depends on the distance an animal's or man's mouth is above the ground. This was especially the case in 1894 , and I do not think the 1896 experience has been much different. In the latter year many isolated cases occurred in houses, but the disease got no further owing to excellent organisation, early detection of cases, and immediate disinfection. The term "house epidemic" has frequently been made use of in previous plague history, but this ought now to make way for "floor" or "flat epidemic." Of course, it may happen that all floors in some houses may be infected at the same time, but from what I have already said it is probably unusual.

(b) Mode of ixection.- "Infection may take place by inoculation, inspiration, or introduction into the stomach." The preponderating method will vary in different epidemics and will depend on the opportunities presented. Rabbits, when inoculated by an incision in the abdomen, generally present appearances of reaction-inflammation and cedemaround the wound. When inoculated in the leg such reaction is sometimes absent. Lymphangitis in man may or may not occur early in the disease, and even if present may give no external evidence of its presence. Some cases may be instructive.

CASE 1.-Professor Aoyama of Tokyo: "On June 28th, at a dinner given by the Japanese doctors to several of the Hong-Kong medical gentlemen connected with the plague Professor Aoyama's temperature was $101 \cdot 6^{\circ} \mathrm{F}$. He slept well during that night. On the morning of the 29 th Dr. Cantlie saw him and found him suffering from what he supposed to be the results of a dissection wound. At 5.30 P.M. he was seen by Dr. Molyneux and myself, and the case being immediately diagnosed as plague he was removed to the Hygeia. From the evidence which we procured it seems that on June 22nd or 23rd, whilst making a post.mortem examination he scratched the left third finger on the posterior and ulnar aspect of the first phalangeal joint.

Medical Report on Bubonic Plagus to the Hong-Kong Government James A. Lowson. 
On June 27th he axain scratched himself on the end of the right thumb. When removed to the Hygeia he had a temperatare of $105^{\circ}$; had a bubo in tho left axilla without 1 ymphangitis; had a well-marked lymphangitis of the right arm extending up to the level of the middle of the humerus." Here there was no lymphangitis at first in what I took to be the plague-infected arm, but it was only non-apparent, as it appeared later, and its intensity can be gauged by the fact that over twenty incisions had to be made in it. Professor Aoyama's own statement is as follows (translated from the German): "On June 28th, after having finished a dissection, I took my meal about half past two and did not enjoy it. After the meal I went upstairs, when at certain movements of the arm I felt a slight pain in the left armpit, and on feeling with my finger I found some slightly enlarged glands present. In the evening I felt very ill, depressed, and languid, burn ing hot along the whole of the back, whilst the thermometer showed normal temperature. As Mr. Kitasato and I had invited guests that evening I was present at supper. I had no appetite and felt so weak and languid that $I$ often wished to withdraw. At half-past eleven I hurried to my room, when I found my temperature was $39.5^{\circ} \mathrm{C}$. I took 1 gramme of quinine and slept well. Next morning I awoke and noticed on the ulnar side of the left ring-finger a small, whitish-yellow blister, and thence along the bark of the hand a red line. From this time I remembered nothing for more than two weeks.". Now on the evening of his removal to the Hygeia and next morning three medical men with as good eyesight as it is possible to have examined him and could not see a trace of lymphangitis in the arm, even when local phalangeal trouble was already evident. The lymphangitis of the right arm was caused by the wound of June 27th. The question as to whether there will be "wound reaction" at the site of infection depends on the purity or impurity of the infecting material and the susceptibility and resisting power of the animal or person inoculated; and in the case of Chinese, who are notoriously susceptible to the disease and have little resisting power, it is little wonder that lymphangitis should be frequently absent seeing that they die usually from the first to the fourth day, before lymphangitis, when it is to occur, has had time to make itself apparent. Lymphangitis may occur late in the disease as a sequela, and when it does it often appears in what was probably the infected limb, of which Case 2 is an example.

CASE 2.-Dr. Ishigami, assistant to Mr. Kitasato. "Examination (June 29th) showed the absence of any open wound on the left hand (he had a left axillary bubo); but there was the mark of a small scar on one of the fingers where he said he had scratched himself some days before.

July 26 th lymphangitis of left arm, treated with lead and opium." I take this as an example of what probably often occurred in the epidemic-inoculation by a small wound, no wound reaction, no lymphangitis within the first few days, but developing later if the patient survived-even this last condition is not at all necessary. No mention of lymphangitis is made by Cerutti, who inoculated six Curopeans to preserve them from the plague, five of them dying. Professor Aoyama and his assistants were always partioularly careful of their hands whilst examining patients in the wards, using carbolic spray, \&s.; but it struck me that in the post-mortem room, where there was far greater danger, they were careless in not using soms antiseptic oil on their hands. Although they washed their hands afterwards in water and alcohol, yet there would be about two hours during the sectio cadaveris in which they could easily get infected.

CASE 3.-A policeman's wife was "admitted with sore between first and second toes, right foot; right femoral bubo and lymphangitis already suppurating." Here there was evidently a mixed infection of plague and streptococcus at once and suppuration was rapid.

These views on inoculation I have given somewhat fully, as this mode of infection has been ridiculed by some medical men in the Far East without having given much atsention to the subject. The mere fact that many plague buboes in the groin and armpit suppurate whilst the internal enlarged glands in the same patient do not seems to bear out the fact that the streptococcus infection is practically stopped at the primary bubo, whilst a secondary piague infection of other glands goes on. The cervical glands rarely suppurated; perhaps in inoculation by the mouth the streptococci had not the same chance of entering the system. In one or two cases multiple abscesses were found, as one occasionally gets a pyæmia after septicæmia; but had these cases been infected by plague alone $I$ do not think suppuration would have been found in disseminated foci. The better class Chinese do not suffer nearly so much from plague. Their houses are slightly cleaner than those of the lower classes, and they wear shoes with the trousers tied tightly round the stockings, thus cutting off a large amount of infecting ground.

Actual proof of infection from food will not be easily proved amongst Eastern races, and may arise from infection of the animals eaten or from infection of food or vegetables which have been exposed in plague houses. Infection by drinking water can only be possible where the most insanitary wells are allowed to exist. It will probably be found that, although the infection be carried to these by flies, mosquitoes \&c., it will not long survive in any well or pool where a free access of air is possible.

\section{Clinital altotes:}

\section{MEDICAL, SURGICAL, OBSTETRICAL, AND THERAPEUTICAL.}

\section{A CASE OF EXOMPHALOS WITH OTHER MALFORMATIONS.}

BY Walter M. WoOdhouse, M.R.C.S. Eng., L.R.C.P. LOND.

SENIOR ASSISTANT MEDICAL OFFICER, KENSINGTON INFIRMARY,

A GIRL, aged twenty years, was admitted into Kensington Infirmary on Nov. 5th, 1896, suffering from syphilis. On examination it was found that she had mucous tubercle round the vaginal orifice and anus, besides a squamous eruption on her skin, which she stated had been there since her ninth year. The patient was thought to be in about the sixth month of pregnancy. Under anti-syphilitic treatment the mucous tubercles cleared up considerably and her general condition greatly improved. On Dec. 18 th the patient had a sudden and somewhat copius hæmorrhage from the vagina. An examination was immediately made and the right foot of a foetus was found to be presenting. After the other foot had been brought down some difficulty was experienced owing to two soft masses which were felt, nne lying posteriorly to the abdomen and the other anteriorly to the head. The former of these was found to be the placenta, and a large swelling seemingly attached to the umbilical region; the latter, a tumour which ruptured prior to delivery, will be presently described. The mother made an uninterrupted recovery and is now to all appearances quite well. The fotus showed no sign of life; at the same time, there was no evidence of maceration.

Necropsy.-The child, a female, was twelve inches in length and, as far as the characteristics would permit one to judge of about from six and a half to seven months' development. Both feet presented well-marked talipes varus. There was a general stunted appearance, the neck being absent, and the head, which was flat at the top with a curiously sloping posterior part, appeared to spring direct from the shouiders. The eyes were prominent and the upper lids seemed much swollen. Dissection proved the absence of the vault of the skull, except some part of the frontal bone, which was pressed back and closely approximated to the anterior part of the base. The roof of the orbit was absent, leaving the eyeball uncovered on its superior aspect, thus explaining the swollen appearance of the eyes. Various foramina for vessels and nerves could plainly be discerned after the skin flaps bad been dissested back. What brain matter there was was contained in a tumour before mentioned over the cervical vertebræ and posterior part of the base of the skull. There was no bony matter behind the usual situation of the foramen magnum, which was absent. The neural arches were deficient over the entire spinal column, leaving the spinal canal unenclosed. Still more remarkable was the arrangement of the abdominal and thoracic viscera. The thorax appeared to be abnormally short. From the region of the umbilicus sprang a pedun culated mass the size of a large orange, the pedicle being an inch in diameter. From the opposite end arose the umbilical 